University of Wollongong

Research Online

Faculty of Engineering - Papers (Archive)

Faculty of Engineering and Information

Sciences

1998

\title{
Tissue equivalence correction for silicon microdosimetry detectors in boron neutron capture therapy
}

\author{
P. D. Bradley \\ University of Wollongong \\ Anatoly B. Rosenfeld \\ University of Wollongong, anatoly@uow.edu.au
}

Follow this and additional works at: https://ro.uow.edu.au/engpapers

Part of the Engineering Commons

https://ro.uow.edu.au/engpapers/151

\section{Recommended Citation}

Bradley, P. D. and Rosenfeld, Anatoly B.: Tissue equivalence correction for silicon microdosimetry detectors in boron neutron capture therapy 1998.

https://ro.uow.edu.au/engpapers/151

Research Online is the open access institutional repository for the University of Wollongong. For further information contact the UOW Library: research-pubs@uow.edu.au 


\title{
Tissue equivalence correction for silicon microdosimetry detectors in boron neutron capture therapy
}

\author{
P. D. Bradley a) and A. B. Rosenfeld \\ Radiation Physics Group, University of Wollongong, Northfields Avenue, Wollongong, \\ NSW, 2522, Australia
}

(Received 17 November 1997; accepted for publication 17 July 1998)

\begin{abstract}
Reverse-biased silicon $p-n$ junction arrays have been proposed as microdosimetry detectors. The tissue equivalence of such detectors in boron neutron capture therapy (BNCT) is discussed. A comparison of the range-energy relationships of $\mathrm{H}, \mathrm{He}, \mathrm{C}$, and Li ions in tissue (ICRU-muscle) and silicon is given. A simple geometrical scaling $(\sim 0.63)$ of linear dimensions is required to convert microdosimetric energy deposition measurements performed in silicon to equivalent deposition in tissue. The Monte Carlo technique is used to examine energy deposition for two simple geometrical cases applicable to BNCT. (c) 1998 American Association of Physicists in Medicine.
\end{abstract}

[S0094-2405(98)00710-X]

Key words: BNCT, microdosimetry, tissue equivalence

\section{INTRODUCTION}

The primary experimental tool for microdosimetric measurements is the proportional gas counter. ${ }^{1}$ Although generally considered the best currently available detector, the proportional gas counter has several shortcomings. These include wall effects, a relatively large physical size, phase effects due to measurement in a gaseous phase, and an inability to simulate an array of cells. ${ }^{1-4}$

McNulty and Roth ${ }^{5}$ proposed the use of arrays of silicon reverse-biased $p-n$ junctions for characterizing complex radiation environments inside spacecraft and aircraft. The work was intended to have applications in determining single event effect (SEE) risks to microelectronics and as a biological microdosimeter for personnel monitoring. Roth ${ }^{6}$ later developed a working model containing more than a million sensitive volumes. Such a detector removes several of the previously mentioned problems associated with proportional gas counters.

More recently, Rosenfeld ${ }^{7}$ has suggested the possibility of simultaneous macro-microdosimetry in a miniature silicon based device. Silicon diode array microdosimetry exploits the rapid development and current manufacturing capabilities of silicon based integrated circuit technology. Furthermore, such arrays offer the possibility of simulating energy deposition in a two-dimensional array of cells.

However, the use of silicon diode arrays as microdosimetric detectors has been impeded by two main problems:

(1) The silicon is not tissue equivalent via a simple density scaling. The macrodosimetric tissue equivalency of silicon or silicon dioxide for integral low Linear Energy Transfer (LET) photon irradiation is well established. ${ }^{8}$ However, methods for converting silicon based microdosimetric measurements to tissue volumes are required.

(2) Accurate definition of the charge collection volume of the reverse biased $p$ - $n$ junction is required. Charge collection occurs via drift, funneling, and diffusion. The funneling and diffusion components increase uncertainty in the sensi- tive volume dimensions. Several methods exist to characterize the sensitive volume parameters such as charge collection spectroscopy techniques. ${ }^{9-11}$

The second problem is the subject of current research and will be discussed in future papers. The first problem of tissue equivalence is addressed in this paper. The results are presented using boron neutron capture therapy (BNCT) as a test case. We first compare silicon and tissue range-energy relationships for $\mathrm{H}, \mathrm{He}, \mathrm{Li}$, and $\mathrm{C}$ ion deposition. The Monte Carlo method is used to compare energy deposition spectra for some simple geometrical cases relevant to boron neutron capture therapy.

\section{COMPARISON OF SILICON AND TISSUE RANGE-ENERGY RELATIONSHIPS}

The primary thermal neutron reactions with tissue are as follows:

$$
\begin{aligned}
& { }_{7}^{14} \mathrm{~N}+{ }_{0}^{1} n \rightarrow{ }_{6}^{14} \mathrm{C}+{ }_{1}^{1} p \quad Q=630 \mathrm{keV}, \\
& { }_{5}^{10} \mathrm{~B}+{ }_{0}^{1} n \rightarrow{ }_{3}^{63 \%} \mathrm{Li}+{ }_{2}^{4} \mathrm{He} \quad Q=2790 \mathrm{keV} \\
& \quad \\
& \quad{ }_{3}^{93.7 \%} \mathrm{Li}+{ }_{2}^{4} \mathrm{He}+\gamma \quad Q=2310 \mathrm{keV} .
\end{aligned}
$$

The ion products and their energies are summarized in Table I. Ion range and energy data for each of these ions was calculated using the computer code SRIM. ${ }^{12}$ The data were calculated for both silicon and tissue using the projected range algorithm (PRAL) option of SRIM. ${ }^{13}$ This option provides range-energy tables that are within a few percent of the more accurate but time consuming TRIM-Monte Carlo calculations available in SRIM. The accuracy of PRAL was considered adequate for our purposes given that we are primarily interested in a comparative study between silicon and tissue. SRIM-Monte Carlo calculations using the ion/energy combinations given in Table I yielded average longitudinal range estimates within $2 \%$ of the PRAL estimated ranges. 
TABLE I. Summary of energy-range data for ions produced by thermal neutron interactions with nitrogen and boron.

\begin{tabular}{ccrrrr}
\hline \hline \multirow{2}{*}{ Reaction } & & & \multicolumn{2}{c}{ Range $(\mu \mathrm{m})$} \\
\cline { 5 - 6 } & Ion & $\begin{array}{c}\text { Energy } \\
(\mathrm{keV})\end{array}$ & Tissue & Silicon \\
\hline${ }^{14} \mathrm{~N}(n, p){ }^{14} \mathrm{C}$ & $p$ & 590 & 10.5 & 7.2 \\
& ${ }^{14} \mathrm{C}$ & 40 & 0.20 & 0.12 \\
${ }^{10} \mathrm{~B}(n, \alpha){ }^{7} \mathrm{Li}$ & $\alpha(6.3 \%)$ & 1780 & 9.3 & 6.3 \\
& ${ }^{7} \mathrm{Li}(6.3 \%)$ & 1010 & 4.6 & 2.8 \\
& $\alpha(93.7 \%)$ & 1470 & 7.7 & 5.1 \\
& ${ }^{7} \mathrm{Li}(93.7 \%)$ & 840 & 4.1 & 2.5 \\
\hline \hline
\end{tabular}

Tissue was modeled as per ICRU striated muscle, which is defined with an elemental composition and density given in Table II. (Ref. 14 and Appendix C in Ref. 1).

Using these models, the range-energy data are plotted in Fig. 1 for the ions relevant to BNCT. A fifth-order polynomial was fitted to each of the ion/target combinations with the results given below.

$\mathrm{H}, \mathrm{He}, \mathrm{Li}$, and $\mathrm{C}$ ions in silicon:

$$
\begin{aligned}
E(r, \mathrm{H}, \mathrm{silicon})= & -0.07492 r^{5}+1.713 r^{4}-13.27 r^{3} \\
& +34.89 r^{2}+80.99 r \\
E(r, \mathrm{He}, \mathrm{silicon})= & -0.2455 r^{5}+15.81 r^{4}-51.49 r^{3} \\
& +198.7 r^{2}+9.229 r, \\
E(r, \mathrm{Li}, \text { silicon })= & 4.398 r^{5}-44.75 r^{4}+141.6 r^{3}-63.99 r^{2} \\
& +141.1 r, \\
E(r, \mathrm{C}, \text { silicon })= & -2.442 \times 10^{6} r^{5}+862600 r^{4}-109200 r^{3} \\
& +5922 r^{2}+211.8 r .
\end{aligned}
$$

$\mathrm{H}, \mathrm{He}, \mathrm{Li}$, and $\mathrm{C}$ ions in muscle (ICRU):

$$
\begin{aligned}
E(r, \mathrm{H}, \text { muscle })= & -0.01148 r^{5}+0.398 r^{4}-4.787 r^{3} \\
+ & 21.2 r^{2}+40.05 r, \\
E(r, \text { He }, \text { muscle })= & 0.00564 r^{5}+0.1188 r^{4}-5.84 r^{3} \\
& +58.06 r^{2}+17.36 r, \\
E(r, \text { Li,muscle })= & 0.03762 r^{5}-1.534 r^{4}+11.73 r^{3} \\
& +6.404 r^{2}+72.66 r, \\
E(r, \mathrm{C}, \text { muscle })= & -1.660 \times 10^{5} r^{5}+97530 r^{4}-20210 r^{3} \\
+ & 1727 r^{2}+146.5 r .
\end{aligned}
$$

The above equations are only valid up to the ion ranges specified in Table I. Comparison of the range-energy relationships for tissue and silicon indicates that the data may be related by a simple scaling factor, $\bar{C}$. Scaling the silicon plots by substituting $0.63 r(\bar{C}=0.63)$ into the above equations yields a close approximation to the tissue range-energy relationship as shown in the right-hand plots of Fig. 1. The ratio $(\bar{C})$ of the ion range in silicon to the range in tissue is only weakly dependent on the ion species and energy.

An average value of $\bar{C}$ was calculated for each ion using
TABLE II. Elemental composition of ICRU striated muscle. $\left(\right.$ Density $=1.04 \mathrm{~g} / \mathrm{cm}^{3}=1.0012 \times 10^{23}$ atoms $/ \mathrm{cm}^{3}$.)

\begin{tabular}{cccc}
\hline \hline Element & $\begin{array}{c}\text { Atomic } \\
\text { number }\end{array}$ & $\begin{array}{c}\text { Atomic } \\
\text { percent }\end{array}$ & $\begin{array}{c}\text { Mass } \\
\text { percent }\end{array}$ \\
\hline $\mathrm{H}$ & 1 & 63.31 & 10.20 \\
$\mathrm{C}$ & 6 & 6.41 & 12.30 \\
$\mathrm{~N}$ & 7 & 1.56 & 3.50 \\
$\mathrm{O}$ & 8 & 28.51 & 72.91 \\
$\mathrm{Na}$ & 11 & 0.02 & 0.08 \\
$\mathrm{P}$ & 15 & 0.04 & 0.20 \\
$\mathrm{~S}$ & 16 & 0.10 & 0.50 \\
$\mathrm{~K}$ & 19 & 0.05 & 0.30 \\
\hline \hline
\end{tabular}

$$
\bar{C}(\text { ion })=\frac{1}{E_{\max }} \int_{0}^{E_{\max }} \frac{R(E, \text { ion, silicon })}{R(E, \text { ion, tissue })} d E,
$$

where $R(E$,ion,target $)$ is the range as a function of energy $(E)$ for the required ion and target. Values of $\bar{C}$ for each ion are shown in Table III. The similarity of these values suggests that by appropriately scaling the sensitive volume dimensions one may achieve similar energy deposition spectra in silicon and muscle cells. The optimum scaling factor, $\bar{C}$, is dependent on the contribution of each ion to the energy deposition spectra which in turn is dependent on the segment length distribution of the sensitive volume, ion energy, and relative frequency of ion generation. An approximate scaling factor was calculated by weighting each ion according to the energy of the ion and the relative frequency of generation. The required cross section and boron and nitrogen concentrations are given in Table IV taken from typical values used by Charlton. ${ }^{15}$ The final weighted average scaling factor is $\bar{C}=0.63$. The maximum deviation from this scaling factor is $8 \%$ and occurs for the highest energy proton.

The scaling factor applies to each linear dimension which means that the mean chord length $[=4$ volume/(surface area)] will also scale by the same factor. For a tissue rectangular parallelepiped (RPP) with dimensions $x \times y \times z$ the required scaling is $\bar{C} x \times \bar{C} y \times \bar{C} z$ of silicon. Note that this holds for any RPP (it is not necessary that $x=y=z$ ) and for other shapes such as a cylinder (the radius and length are scaled) or a sphere (radius scaling only).

\section{COMPARISON OF SILICON AND TISSUE BNCT ENERGY DEPOSITION SPECTRA}

\section{A. Method: Monte Carlo program}

A Monte Carlo program was developed in order to confirm that the energy deposition in appropriately scaled silicon volumes may approximate the deposition in tissue. The use of Monte Carlo methods to calculate microdosimetric spectra in cell sized volumes exposed to BNCT and other high LET ions is well established. ${ }^{15}$ It is generally assumed that the path of the ions follow straight lines with negligible straggling and that the width of the track is negligible in comparison to the volume size. These assumptions are valid for micrometer sized volumes and low energy ions as confirmed by 

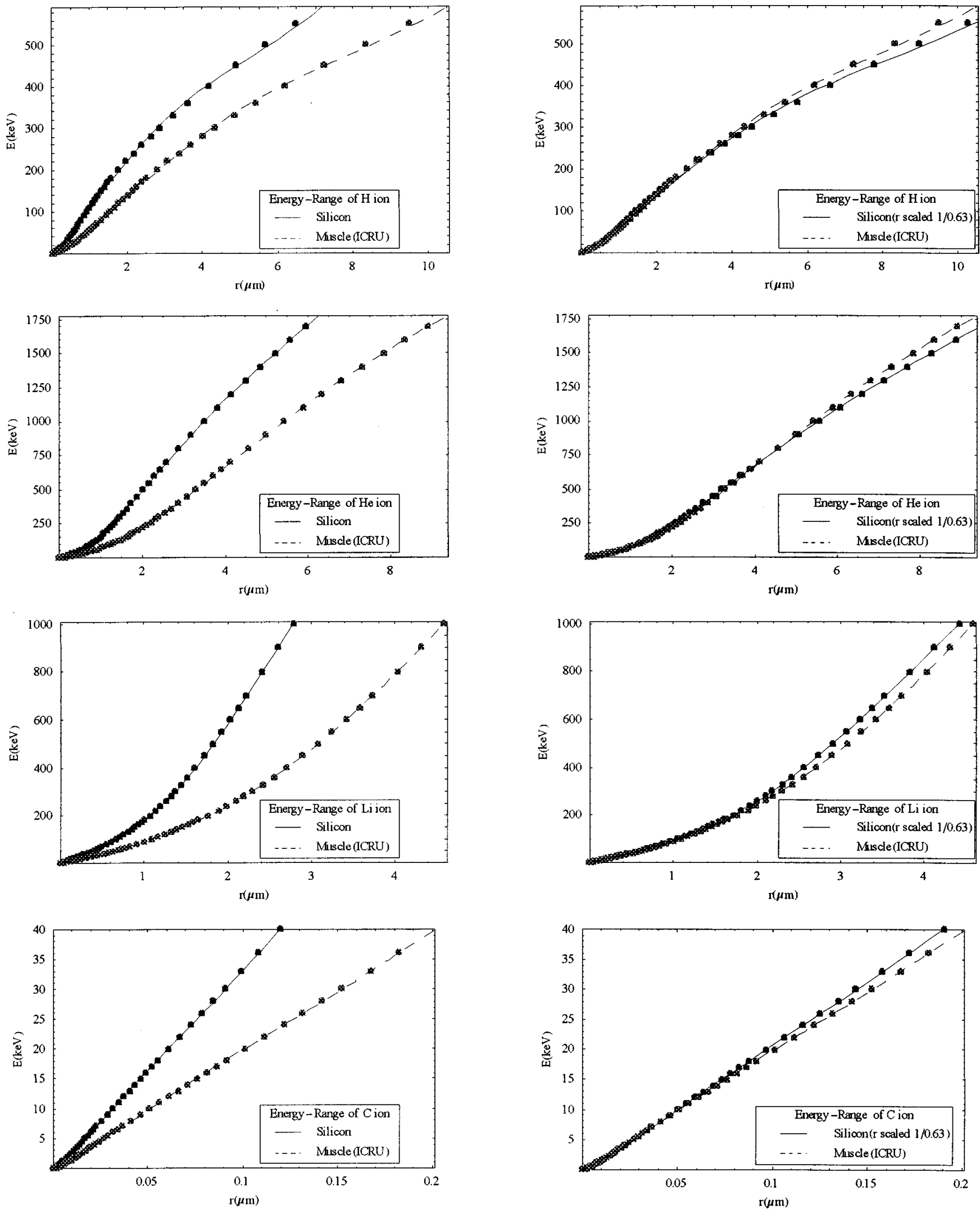

FIG. 1. Range-energy relationships for $\mathrm{H}, \mathrm{He}, \mathrm{Li}$, and $\mathrm{Si}$ in ICRU muscle and silicon. The right-hand side shows the same plot as the left except for the silicon range scaled by $1 / 0.63$. In addition, the left plot displays original SRIM generated data points used for the fifth-order polynomial fit. 
TABLE III. Mean ratio of ion ranges.

\begin{tabular}{lcc}
\hline \multicolumn{1}{c}{ Ion } & $\bar{C}$ & Weight $^{\mathrm{a}}$ \\
\hline $\mathrm{H}$ & 0.65 & 0.13 \\
$\mathrm{He}$ & 0.64 & 0.55 \\
$\mathrm{Li}$ & 0.60 & 0.31 \\
$\mathrm{C}$ & 0.60 & 0.01 \\
Weighted Av. & 0.63 & \\
\hline
\end{tabular}

${ }^{a}$ Weight is an approximate measure of the contribution of the ion to BNCT energy deposition spectra.

comparative calculations performed by Charlton $^{16}$ on detailed track structure versus simple chord length LET calculations.

The program description begins by defining two types of volumes;

(1) Generation volume $(\mathrm{GV})$ in which ions are generated assuming a nitrogen concentration of $3.5 \mathrm{~g} / 100 \mathrm{~g}$ and a boron concentration of $20 \mu \mathrm{g} / \mathrm{g}$. The probability of formation of the various ion pairs and the number of interactions per $\mu \mathrm{m}^{3}$ are given in Table II.

(2) Sensitive volume (SV) in which we compute the energy deposited by the traversal of ions generated in the GV.

The shape of both volumes is defined as an RPP with dimensions $x \times y \times z$ all in $\mu \mathrm{m}$. Such a shape is selected on the basis that the $\mathrm{SV}$ of silicon reverse biased $p$ - $n$ junctions has traditionally been modeled as a RPP. The position of the $\mathrm{GV}$ with respect to the SV has no restriction with partial or even complete overlapping allowed.

The Monte Carlo process may be summarized by the following steps:

(1) Randomly select an ion pair with initial energy and range given by Table I according to the probability specified in Table IV.

(2) Randomly select the position of the interaction within the GV and the angle of ion emission with equal probability for all points within the $\mathrm{GV}$ and all angles. Note that ion pairs are emitted at $180 \mathrm{deg}$.

(3) Calculate the points of intersection of the emitted ions with the SV. This may be approached by solving the simultaneous equations of a line intersecting a RPP in a similar manner as Charlton ${ }^{15}$ for an ellipsoid. Alternatively, one may

TABLE IV. Summary of interaction data for selected BNCT conditions. ${ }^{\text {a }}$

\begin{tabular}{|c|c|c|c|c|}
\hline Reaction & $\begin{array}{c}\sigma \text { (barns/ } \\
\text { atom) }\end{array}$ & $\begin{array}{c}\text { Interactions/ } \\
\qquad \mu \mathrm{m}^{3}\end{array}$ & Ion & $\begin{array}{c}P(\text { ion pair } \\
\text { emitted })\end{array}$ \\
\hline${ }^{14} \mathrm{~N}(n, p){ }^{14} \mathrm{C}$ & 1.81 & 0.0272 & $\begin{array}{c}p \\
{ }^{14} \mathrm{C}\end{array}$ & 0.37 \\
\hline${ }^{10} \mathrm{~B}(n, \alpha){ }^{7} \mathrm{Li}$ & 3837 & 0.0462 & $\begin{array}{c}\alpha(6.3 \%) \\
{ }^{7} \mathrm{Li}(6.3 \%) \\
\alpha(93.7 \%) \\
{ }^{7} \mathrm{Li}(93.7 \%)\end{array}$ & $\begin{array}{l}0.04 \\
0.59\end{array}$ \\
\hline
\end{tabular}

${ }^{\mathrm{a} B}$ Both reactions are for a neutron fluence of $10^{13} \mathrm{n} / \mathrm{cm}^{2}$. Nitrogen concentration $3.5 \mathrm{~g} / 100 \mathrm{~g}$. Boron concentration $20 \mu \mathrm{g} / \mathrm{g}$. For other concentrations and fluence the interactions per unit volume changes proportionally. $P$ (ion pair emitted) is the proportion of interactions which produce the respective ion pair.

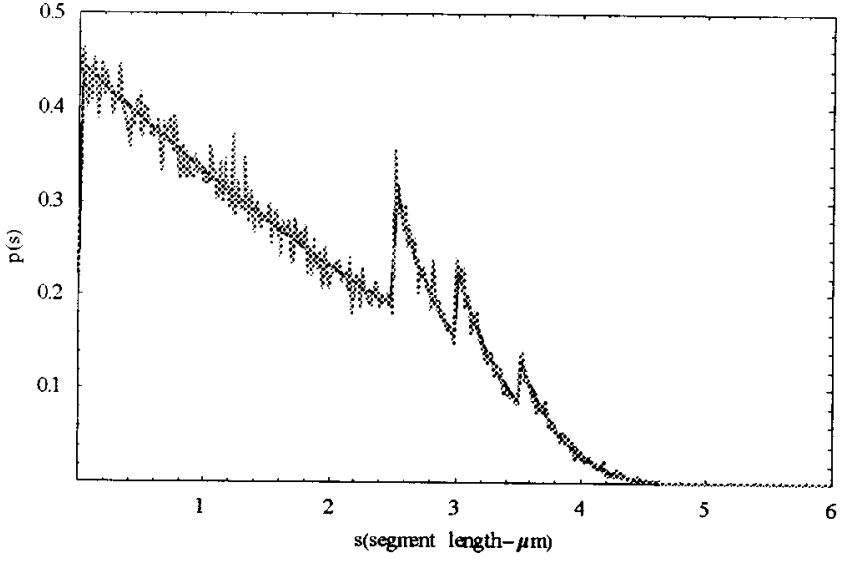

FIG. 2. Comparison of analytic and Monte Carlo generated segment length distribution $(P(s))$ for a RPP volume $3.5 \times 3 \times 2.5 \mu \mathrm{m}$ enclosed in a uniform isotropic field of $7 \mu \mathrm{m}$ length rays.

incrementally follow the ion path at sufficiently small increments $(0.01 \mu \mathrm{m})$, testing at each increment to check for traversal of the SV boundary. The latter approach was adopted despite the longer computation time since it is more adaptable to future versions that may operate on complex geometry.

The main Monte Carlo routines were coded in $\mathrm{C}$ for computational speed. These routines were encapsulated within a MATHEMATICA based input/output framework to provide flexibility in program input and output analysis.

Software validation of such programs is a nontrivial task since it is often difficult to construct cases of sufficient simplicity that analytic solutions may be derived for result comparison. The software was modified slightly to calculate segment length distributions. Such distributions have been analytically derived by Bradford ${ }^{17}$ (based on the work of Kellerer ${ }^{18}$ ) for a RPP volume under the condition of $\mu$ randomness and fixed length tracks. $\mu$-randomness ${ }^{18}$ refers to the generation of straight ion tracks within a uniform isotropic field of infinite extent. The author calculated exact segment length distributions and compared such distributions with the Monte Carlo results. Figure 2 displays the close correspondence between the analytic and Monte Carlo de-

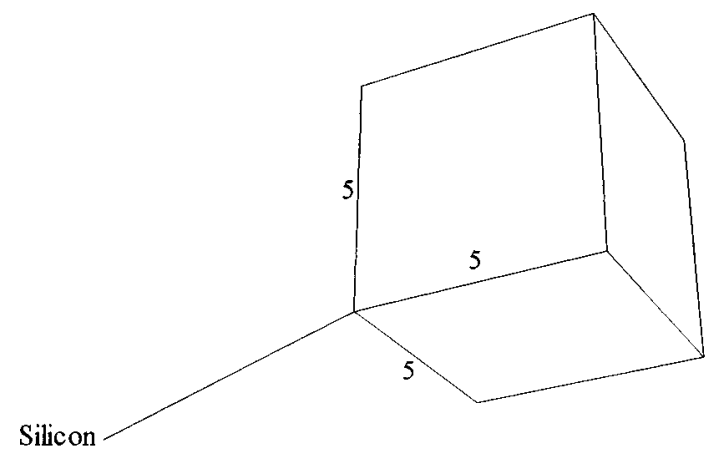

Rest: Silicon

FIG. 3. Geometry Case $1-\mathrm{SV}$ and GV are identical in size and position. 


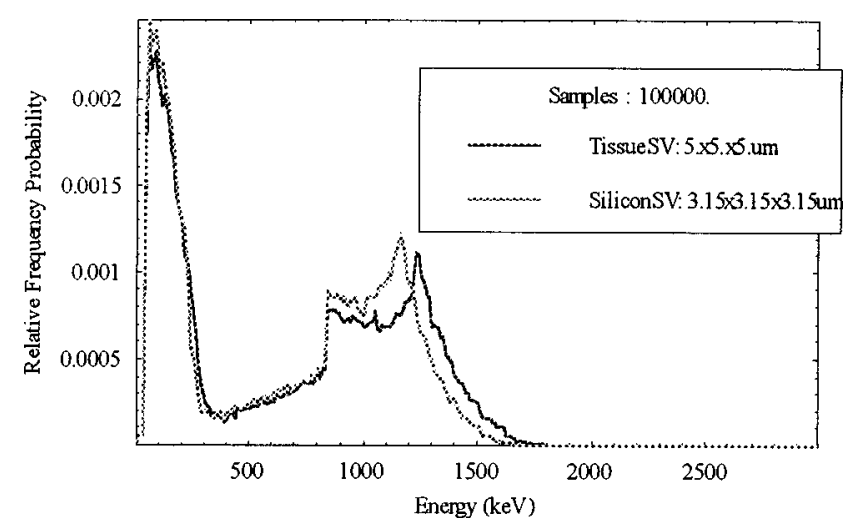

FIG. 4. Geometry Case 1 (Example 1): Energy deposition spectra comparison of silicon $(3.15 \times 3.15 \times 3.15 \mu \mathrm{m})$ and tissue $(5 \times 5 \times 5 \mu \mathrm{m})$.

rived distributions thus validating a substantial portion of the software. The remainder of the software was tested by thorough review and testing of individual functions.

\section{B. Results: Geometry Case 1-lon generation in RPP volumes with $\mathbf{S V}=\mathbf{G V}$}

Geometry Case 1 consists of identical SV and GV of the same material (silicon or tissue). Figure 3 illustrates the case for a $5 \times 5 \times 5 \mu \mathrm{m}$ volume of silicon. We assume that both silicon and tissue contain the same concentration of boron and nitrogen. This case corresponds to the BNCT scenario in which a B-10 compound is uniformly distributed throughout the cell. However, a corresponding silicon detector cell is limited to measuring only the boron capture component. Boron may be easily introduced by using $p$ doped $\mathrm{Si}$ arrays as proposed by Rosenfeld. ${ }^{7}$ The introduction of nitrogen into the body of a silicon diode is a much more difficult proposition. Nitrogen concentrations required for an acceptable probability of nitrogen capture are too high for maintaining device operation. Note, that nitrogen may be introduced into surrounding insulating layers (e.g., $\mathrm{Si}_{3} \mathrm{~N}_{4}$ is commonly used for passivation). Nevertheless, for the purpose of testing the tissue/silicon scaling factor, we compare a hypothetical device assuming tissue concentrations of nitrogen and boron.

Figures 4 and 5 illustrate the energy deposition spectra

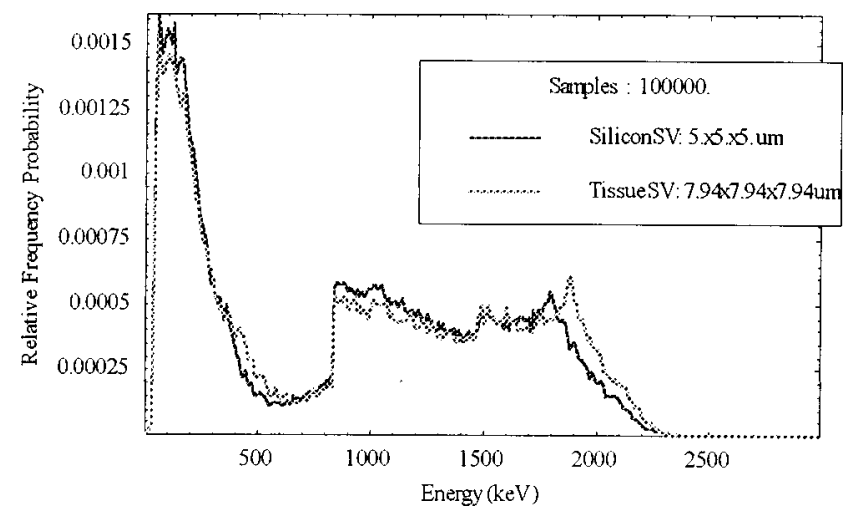

FIG. 5. Geometry Case 1 (Example 2): Energy deposition spectra comparison of silicon $(5 \times 5 \times 5 \mu \mathrm{m})$ and tissue $(7.9 \times 7.9 \times 7.9 \mu \mathrm{m})$.

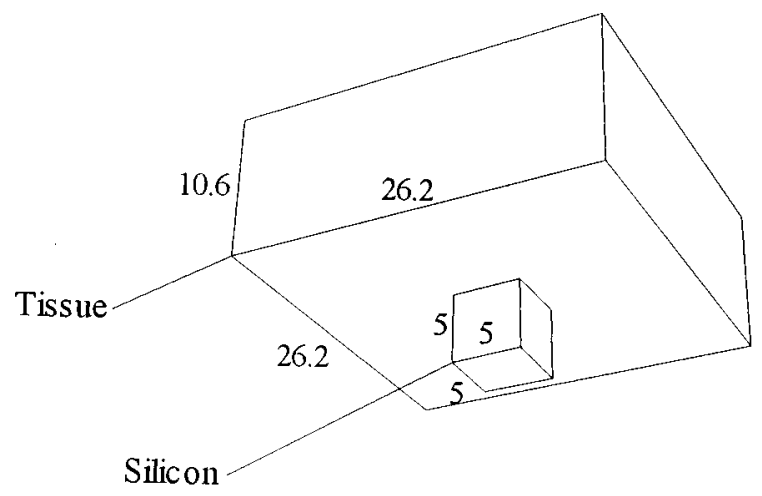

Rest: Silic on

FIG. 6. Geometry Case $2-\mathrm{GV}$ is a large tissue volume above a much smaller silicon/tissue SV.

(normalized) for silicon and tissue with the dimensions of silicon scaled by 0.63 in each case. Clearly, the energy deposition spectra are vastly different for similar volumes of tissue and silicon. However, a comparison of silicon volumes scaled by $\bar{C}=0.63$ with tissue volumes indicates quite good correspondence between spectra.

\section{Results: Geometry Case 2-Ion generation above RPP volume}

Geometry Case 2 consists of a large GV placed directly on top of a much smaller SV. The GV material is tissue while the remaining volume including the SV consists of either tissue or silicon. This case is not hypothetical since it is easy to construct an overlayer with the appropriate concentrations of boron and nitrogen without compromising silicon device operation. Figure 6 illustrates the case for a silicon SV of dimensions $5 \times 5 \times 5 \mu \mathrm{m}$. The GV dimensions are selected such that the boundaries are further from the SV than the longest range ion $(590 \mathrm{keV}$ proton-10.5 $\mu \mathrm{m})$. Thus, we effectively model a volume of infinite extent away from the SV. Such a situation models a layer of tissue equivalent plastic (or real cells) impregnated with appropriate boron concentrations and placed above a silicon cell (within an integrated circuit). We then compare the energy deposition in

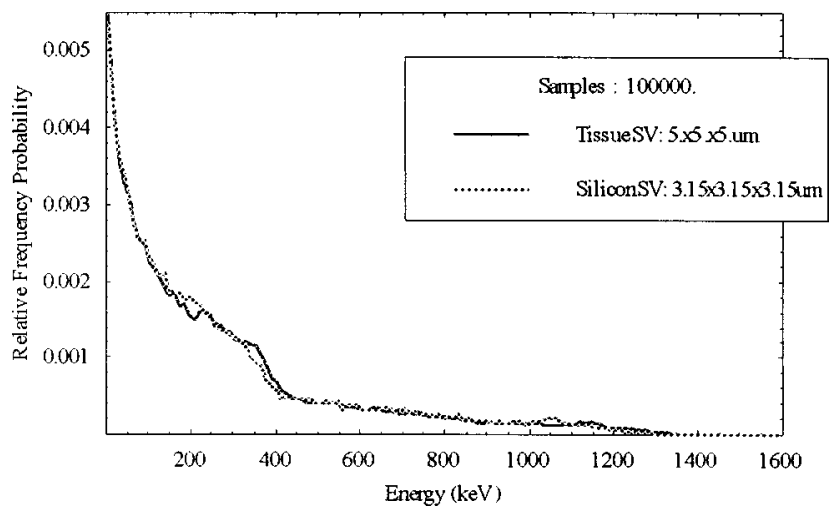

FIG. 7. Geometry Case 2 (Example 1): Energy deposition spectra comparison of silicon $(3.15 \times 3.15 \times 3.15 \mu \mathrm{m})$ and tissue $(5 \times 5 \times 5 \mu \mathrm{m})$. 


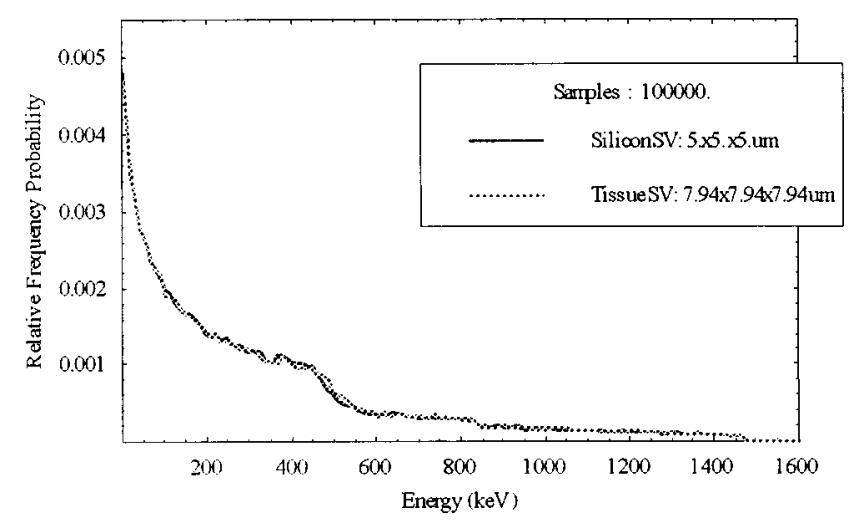

FIG. 8. Geometry Case 2 (Example 2): Energy deposition spectra comparison of silicon $(5 \times 5 \times 5 \mu \mathrm{m})$ and tissue $(7.9 \times 7.9 \times 7.9 \mu \mathrm{m})$.

an appropriately scaled silicon cell to that which may occur if a tissue cell was substituted as the SV. Again the normalized results shown in Figs. 7 and 8 confirm that, with appropriate geometrical scaling, silicon detectors with well-known geometry will record energy deposition spectra representative of tissue cells of equivalent shape. Again, note the significant differences in spectra between the two figures (tissue $5 \times 5 \times 5 \mu \mathrm{m}$ in Fig. 7 and silicon $5 \times 5 \times 5 \mu \mathrm{m}$ in Fig. 8) indicating the importance of using an appropriate scaling factor.

\section{SUMMARY AND CONCLUSIONS}

A Monte Carlo program was developed to simulate the energy deposition of ions in a BNCT radiation field. The Monte Carlo results confirm that with appropriate geometrical scaling (0.63) silicon detectors with well-known geometry will record energy deposition spectra representative of tissue cells of equivalent shape. That is, silicon is tissue equivalent for BNCT under appropriate linear geometrical scaling.

These results also assist in validating a new approach to microdosimetry in radiation oncology using silicon detector arrays with varying space localization of B-10 relative to the cell. ${ }^{7}$ This paper demonstrates that extensive study of charge collection in micron sized silicon volumes may lead to the creation of a new class of microdosimeters for high LET radiation fields. A tissue equivalence correction method for BNCT has been determined but further work is required to investigate the tissue equivalence of silicon microdosimeters in other high LET environments such as heavy ion, fast neutron and proton therapy modalities. Dosimetry in these developing therapies has traditionally been quite difficult.

Future work is being directed toward the experimental study of high LET radiation deposition in silicon $p-n$ junction arrays of well-known sensitive volume geometry.

\section{ACKNOWLEDGMENTS}

The authors would like to thank James Ziegler (IBM) for the latest copy of SRIM and Peter McNulty (Clemson University) for some preliminary discussions. This work was funded by Australian National Health and Medical Research Council Grant No. 960804.

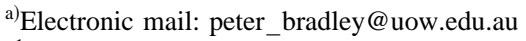

${ }^{1}$ International Commission on Radiation Units and Measurements, Microdosimetry, ICRU Report No. 36 (ICRU, Maryland, 1993).

${ }^{2}$ H. H. Rossi and M. Zaider, Microdosimetry and Its Applications (Springer, London, 1996).

${ }^{3}$ P. Kliauga, "Microdosimetry at Middle Age: Some Old Experimental Problems and New Aspirations," Radiat. Res. 124, 5-15 (1990).

${ }^{4}$ A. M. Kellerer, "Event simultaneity in cavities. Theory of the distortions of energy deposition in proportional counters," Radiat. Res. 48, 216 (1971).

${ }^{5}$ P. J. McNulty, D. R. Roth, E. G. Stassinopoulos, and W. J. Stapor, "Characterizing complex radiation environments using MORE (monitor of radiation effects)," in Symposium Detector Research and Development SSC, edited by T. Dombeck, V. Kelly, and G. P. Yost (World Scientific, Singapore, 1990), pp. 690-692.

${ }^{6}$ D. R. Roth, P. J. McNulty, W. J. Beauvais, R. A. Read, and E. G. Stassinopoulos, "Solid-state microdosimeter for radiation monitoring in spacecraft and avionics,"' IEEE Trans. Nucl. Sci. 41, 2118-2124 (1996).

${ }^{7}$ A. B. Rosenfeld, G. I. Kaplan, M. G. Carolan, B. J. Allen, R. Maughan, M. Yudelev, C. Kota, and J. Coderre, "Simultaneous macro-micro dosimetry with MOSFETs," IEEE Trans. Nucl. Sci. 43, 2693-2700 (1996). ${ }^{8}$ A. B. Rosenfeld, M. G. Carolan, G. I. Kaplan, B. J. Allen, and V. I. Khivrich, "MOSFET dosimeters: The role of encapsulation on dosimteric characteristics in mixed gamma-neutron and megavoltage X-ray fields," IEEE Trans. Nucl. Sci. 42, 1870-1877 (1996).

${ }^{9}$ W. G. Abdel-Kader, P. J. McNulty, S. El-Teleaty, J. Lynch, and A. N. Khondker, "Estimating the dimensions of the SEU-sensitive volume," IEEE Trans. Nucl. Sci. 34, 1300-1303 (1987).

${ }^{10}$ P. J. McNulty, W. J. Beavais, and D. R. Roth, "Determination of SEU parameters of NMOS and CMOS SRAMs," IEEE Trans. Nucl. Sci. 38, 1463-1470 (1993).

${ }^{11}$ R. A. Reed, P. J. McNulty, W. J. Beavais, and D. R. Roth, "Charge Collection Spectroscopy,' IEEE Trans. Nucl. Sci. 40, 1876-1884 (1993).

${ }^{12}$ J. F. Ziegler, SRIM: The Stopping and Range of Ions in Matter (Computer Program, Version 97.02) (IBM Research, Yorktown, 1997).

${ }^{13}$ J. F. Ziegler, J. P. Biersack, and U. Littmark, The Stopping and Range of Ions in Solids (Pergamon, New York, 1985), pp. 155-164.

${ }^{14}$ International Commission on Radiation Units and Measurements, Physical Aspects of Irradiation (ICRU Report No. 10b, published as National Burean of Standards Handbook 85) (ICRU, Maryland, 1964).

${ }^{15}$ D. E. Charlton and B. J. Allen, "Monte Carlo calculations of ion passages through brain endothelial nuclei during boron neutron capture therapy," Int. J. Radiat. Biol. 64, 739-747 (1993).

${ }^{16}$ D. E. Charlton, D. T. Goodhead, W. E. Wilson, and H. G. Paretze, "Energy deposition in Cylindrical Volumes: (a) Protons, Energy 0.3 MeV to 4.0 MeV, (b) Alpha Particles, 1.2 MeV to $20 \mathrm{MeV}$,' Monograph 85/1 (Medical Research Council, Chilton, 1985).

${ }^{17} \mathrm{~J}$. N. Bradford, "Single event error generation by $14 \mathrm{MeV}$ neutrons reactions in silicon," IEEE Trans. Nucl. Sci. 27, 1480-1484 (1980).

${ }^{18}$ A. M. Kellerer, "Considerations on the random traversal of convex bodies and solutions for general cylinders," Radiat. Res. 47, 359-376 (1971). 